\title{
Article
}

\section{Students Fail to Transfer Knowledge of Chromosome Structure to Topics Pertaining to Cell Division}

\author{
Dina L. Newman, ${ }^{*}$ Christina M. Catavero, and L. Kate Wright*
}

School of Life Sciences, Rochester Institute of Technology, Rochester, NY 14623

Submitted January 10, 2012; Revised June 14, 2012; Accepted July 12, 2012

Monitoring Editor: James Hewlett

\begin{abstract}
Cellular processes that rely on knowledge of molecular behavior are difficult for students to comprehend. For example, thorough understanding of meiosis requires students to integrate several complex concepts related to chromosome structure and function. Using a grounded theory approach, we have unified classroom observations, assessment data, and in-depth interviews under the theory of knowledge transfer to explain student difficulties with concepts related to chromosomal behavior. In this paper, we show that students typically understand basic chromosome structure but do not activate cognitive resources that would allow them to explain macromolecular phenomena (e.g., homologous pairing during meiosis). To improve understanding of topics related to genetic information flow, we suggest that instructors use pedagogies and activities that prime students for making connections between chromosome structure and cellular processes.
\end{abstract}

\section{INTRODUCTION}

Chromosome structure and behavior are topics that are notoriously difficult for students to grasp, leading to gaps in student understanding of complex processes involving chromosomes and inheritance. Genetics is an intricate subject that relies on thoroughly understanding the structure and molecular behavior of information-carrying chromosomes, and many students struggle with this subject. Even though instruction on chromosomes often begins in a middle school science class, students have difficulty understanding the process of meiosis; this phenomenon has been documented for more than 30 yr (Johnstone and Mahmoud, 1980; Stewart and Dale, 1989; Stewart et al., 1990; Kindfield, 1991, 1994b; Dikmenli, 2010; Wright and Newman, 2011). Although this is a widely recognized problem, and many teaching approaches have been devised to attempt to solve it, little progress has

DOI: $10.1187 /$ cbe.12-01-0003

Address correspondence to: Dina L. Newman (dina.newman@ rit.edu).

*These authors contributed equally to the work.

(c) 2012 D. L. Newman et al. CBE-Life Sciences Education (c) 2012 The American Society for Cell Biology. This article is distributed by The American Society for Cell Biology under license from the author(s). It is available to the public under an AttributionNoncommercial-Share Alike 3.0 Unported Creative Commons License (http:/ / creativecommons.org/licenses/by-nc-sa/3.0).

"ASCB $\left.{ }^{(}\right)$" and "The American Society for Cell Biology ${ }^{\circledR}$ " are registered trademarks of The American Society for Cell Biology. been made, and no systematic studies have been undertaken to determine what students are thinking when they work on meiosis-related problems. The few studies that have been published focus on misconceptions rather than on foundational knowledge and scaffolding. Deeply ingrained misconceptions concerning the complex processes of meiosis, cell division, and genetics have been well documented (Fisher et al., 1986; Brown, 1990; Kindfield, 1994a; Bahar et al., 1999; Lewis et al., 2000; Marbach-Ad, 2001; Dikmenli, 2010), with several studies pointing to the difficulties students have in explaining the molecular basis of inheritance (Marbach-Ad, 2001; Wood-Robinson et al., 2000). Although experts have identified several common misconceptions and difficulties with the topics, it is not clear why students embrace these ideas, or why it is so difficult to change their conceptual models. Concepts linked to cell division and meiosis are crucial to a clear understanding of numerous facets of life, including reproduction, cell biology, genetics, and evolution, but little has changed in the way in which these subjects are taught, and comprehension has not improved (Dikmenli, 2010).

Through a partnership between the National Society of Genetic Counselors and the American Society of Human Genetics, high school students from across the nation participated in an essay-writing contest as part of National DNA Day (Mills Shaw et al., 2008). Thorough analysis of 500 essays (from the 2443 collected over the 2 -yr contest) revealed a very interesting finding: Students in 2007 held the same genetics misconceptions as students in 2000 (from a comparable study by the National Assessment of Educational Process), despite the expansion of genetics information and 
technology that occurred during the same time period. Not surprisingly, patterns of inheritance was found to be the second most-confusing topic for these high school students. In a higher education example, out of 409 undergraduate students recently enrolled in a genetics course (multiple offerings with multiple instructors over the course of $2 \mathrm{yr}$ at a large-enrollment private institution), 74 students $(18 \%)$ either withdrew or failed the course (R. Rothman and M. Osier, personal communication).

Two of the most commonly held student misconceptions about meiotic cell division relate to chromosome structure. Through in-depth interviews with experts, experienced novices, and true novices (undergraduate students) about meiosis problems, Kindfield (1991, 1994a,b) documented that "students often believe that chromosome structure is a function of chromosome number or ploidy." She argued that in order for students to correctly understand ploidy, they must think of chromosomes, both replicated and unreplicated, as discrete entities, and suggested that instructors "clearly identify the origin of two-DNA-molecule entities" and "clearly distinguish between the concepts of chromosome structure and chromosome number" to help overcome cognitive stumbling blocks. Another common problem is that students incorrectly believe that two-DNA molecule chromosomes in diploid cells (formed by replication) arise by the fusion of two single-DNA molecule chromosomes, one from each parent. This "formation-by-fertilization" misconception, first reported by Smith (1991), can severely impede students' ability to understand the main point of meiosis (to generate gametes for later fertilization steps).

One outcome of findings such as these has been the construction of new learning assessment tools. The Genetics Literacy Assessment Instrument (GLAI; Bowling et al., 2008) has eight of 31 questions devoted to the topics being explored in this manuscript: nature of genetic material and transmission. The Genetics Concept Assessment (GCA), another instrument created to assess student learning gains in a typical college-level genetics course, has 11 of 25 questions designed to assess whether students can correctly describe "the molecular anatomy of genes and genomes," "mechanisms by which an organism's genome is passed on to the next generation," and "phenomenon of linkage and how it affects assortment of alleles during meiosis" (Smith et al., 2008). The Introductory Molecular and Cell Biology Assessment (IMCA) (Shi et al., 2010) also was utilized by us, as it contained two of 24 questions dedicated to topics being investigated here. A subset of the learning goals tested by these question sets is dependent on students using their knowledge of chromosome structure to answer higher-order questions about genetics and information transfer. Validated assessments such as these are valuable tools that allow instructors to gain insight into what concepts their students are struggling with, but not necessarily why they struggle with particular topics.

In this study, we show that biology students do not think about the molecular and genetic aspects of chromosomes when describing meiosis or trying to make sense out of chromosomal behavior. We hypothesize that students do not transfer their knowledge pertaining to chromosome structure when thinking about complex cellular processes such as cell division. Our work suggests that students have difficulty transferring their mental models of DNA to the context of chromosome structure.
For this work we describe "transfer" as the ability to "extend what has been learned in one context to new contexts" (Bransford and Schwartz, 1999). We are not assessing whether students transfer knowledge between academic and everyday life, or whether they use knowledge appropriately across cultural boundaries (Lave, 1988). Instead, we are framing our discussion on the transfer of knowledge between two topics within the context of biology, which would most closely align with the definition of "near transfer" described by Perkins and Salomon (1992).

The theory of transfer is relevant to understanding student thinking and learning (Mestre, 2005) and has been used to explain various phenomena in the educational research literature. For example, work from a multipart study by Kelly and Jones $(2007,2008)$ focused on transfer of knowledge in the context of undergraduate chemistry students understanding salt dissolution. Students were asked to draw their models of solid sodium chloride $(\mathrm{NaCl})$ and liquid water before viewing an animation about $\mathrm{NaCl}$ dissolution. Analysis of students' drawings, as well as semistructured interviews, demonstrated that all students (18 out of 18$)$ made improvements to their models, especially in the topics of structure and function, after viewing the animation. One week later, the same 18 students watched a video demonstrating the precipitation of silver chloride $(\mathrm{AgCl})$ after solutions of $\mathrm{NaCl}$ and silver nitrate $\left(\mathrm{AgNO}_{3}\right)$ were mixed. Students were asked to draw and explain what they viewed during the video demonstration. Although 12 out of 18 (67\%) students said they remembered and thought about the first animation during the second exercise, only two of the 12 correctly drew $\mathrm{NaCl}$ as separated ions in their models. None of the students correctly drew the spheres of hydration forming around ions during dissolution, even though all had included this element in their previous model $1 \mathrm{wk}$ earlier. With interviewer prompting, nine out of 15 students were eventually able to change their models to show the correct separation of $\mathrm{Na}^{+}$and $\mathrm{Cl}^{-}$ ions. While this is an excellent example of lack of transfer, why students were unable to make the connection from the first to the second demonstration is an interesting and complex question that remains unresolved. In an excellent review of the transfer literature, Barnett and Ceci (2002) point out that "there is little agreement in the scholarly community about the nature of transfer, the extent to which it occurs, and the nature of its underlying mechanisms."

We used a grounded theory approach (Martin and Turner, 1986; Strauss and Corbin, 1997; Creswell, 2007) to unify our classroom observations and assessment and interview data collected from various courses and student populations. Using a grounded theory keeps "researchers close to their gathered data rather than to what they may have previously assumed or wished was the case" (Holstein and Gubrium, 2003). This approach allowed us to identify key features and themes that were repeated within different contexts (introductory through advanced biology courses) and with different students (first year through senior level) from which a free-flowing hypothesis emerged, instead of data packaged to fit within a prescribed hypothesis. In this same vein, emergent coding strategies were used for analysis of data sets so that, after some initial assessment, key categories and ideas could be identified.

These approaches strengthen our argument that knowledge transfer may be the root cause of the student confusion 
Table 1. Questions used to evaluate student understanding of chromosome structure

\begin{tabular}{|c|c|c|}
\hline Class Tested & Question & Source \\
\hline Introduction to Biology (freshmen) & $\begin{array}{l}\text { What is the relationship between DNA and chromosomes in higher } \\
\text { organisms? }\end{array}$ & GLA $^{\text {a }}$ (question 16) \\
\hline $\begin{array}{l}\text { Introduction to Biology and Molecular } \\
\text { Bio (sophomores) }\end{array}$ & What is the relationship among genes, DNA, and chromosomes? & GLA (question 1) \\
\hline Cell Biology (sophomores) & $\begin{array}{l}\text { Describe the relationship between chromosomes, DNA, and genes. } \\
\text { [open response] }\end{array}$ & This paper \\
\hline Cell Biology and Molecular Biology & $\begin{array}{l}\text { The photograph below shows a single replicated chromosome } \\
\text { (consisting of two sister chromatids) just before mitosis. This } \\
\text { chromosome contains... [number of single-/double-stranded } \\
\text { molecules] }\end{array}$ & $\mathrm{IMCA}^{\mathrm{b}}$ (question 19) \\
\hline Cell Biology and Molecular Biology & $\begin{array}{l}\text { The replicated chromosome shown in question } 19 \text { contains... [DNA } \\
\text { from how many parents?] }\end{array}$ & IMCA (question 20) \\
\hline \multirow[t]{4}{*}{ Human Genetics (juniors/seniors) } & $\begin{array}{l}\text { A man is a carrier for Wilson's disease (Aa) and Rotor syndrome (Rr). } \\
\text { Assume the genes involved in these two disorders are both on } \\
\text { chromosome } 13 \text { (a non-sex chromosome). Below are possible } \\
\text { representations of his genotype... Which of them could be correct? } \\
\text { [representation of genes A and R on same chromosome or different; } \\
\text { recessive alleles on same chromosome or different] }\end{array}$ & GCA $^{c}$ (question 13) \\
\hline & $\begin{array}{l}\text { Suppose there are two genes on two different chromosomes, one gene } \\
\text { called G and the other called D. An individual has the genotype } \\
\text { GgDd. Which of the following drawings correctly shows cells in this } \\
\text { individual after DNA replication but before cell division of the first } \\
\text { meiosis? [representations of alleles on sister chromatids vs. } \\
\text { homologous chromosomes] }\end{array}$ & GCA (question 23) \\
\hline & $\begin{array}{l}\text { In the germline cell below there are two pairs of chromosomes on which } \\
\text { are shown the locations of two different genes. F and f represent two } \\
\text { different alleles (versions or variants) of one gene, and } Q \text { and } q \\
\text { represent two different alleles of another gene. If this cell divides } \\
\text { normally to produce sperm, what are the possible sperm genotypes? } \\
\text { [unreplicated chromosome representations of unlinked genes] }\end{array}$ & GCA (question 2) \\
\hline & $\begin{array}{l}\text { Sue's chromosome \#18 pair looks like this: [A and A, unreplicated } \\
\text { representation] Bob's chromosome \#18 pair looks like this: [A and a, } \\
\text { unreplicated] Bob and Sue have a stillborn son with three copies of } \\
\text { chromosome \#18 that look like this: [A and A and A, unreplicated] In } \\
\text { which parent did the chromosome separation problem occur? }\end{array}$ & GCA (question 20) \\
\hline \multicolumn{3}{|l|}{$\begin{array}{l}\text { bShi et al., } 2010 . \\
\text { 'Smith et al., } 2008 .\end{array}$} \\
\hline
\end{tabular}

presented here, and our results are not isolated findings that are course- or instructor-dependent. We show, through coded worksheet data, modeling exercises, and student interviews, that undergraduate biology students know about chromosome composition and structure but fail to utilize this knowledge in the context of cell division (mitosis and meiosis) and transmission of genetic information.

\section{MATERIALS AND METHODS}

All of the following protocols were approved by the Institutional Review Board, Rochester Institute of Technology, and informed consent was acquired from all research subjects. Pseudonyms are used throughout this paper to ensure confidentiality.

\section{Student Assessments}

We took a holistic view of the phenomenon by examining student mental models in a group of undergraduates at levels ranging from novice (freshman course) to advanced biology students (upper-level elective). Data were generated by biology students in several different courses at a large private institution, as follows. Multiple-choice questions (MCQ) from concept inventories and one open-ended response question were used for assessments in classroom settings (see Table 1).

A number of instruments were used in a series of different classes, as described below. In each case, the assessments were given as in-class pretests before instruction to help inform us of student knowledge on the particular topic and student understanding across the curriculum.

To investigate students' prior knowledge about the relationship between DNA, genes, and chromosome structure, we administered questions from the GLAI (Bowling et al., 2008) to students in an introductory biology course $(n=71)$ and in a midlevel molecular biology course $(n=96)$. Students who completed these assessments were either first-year biology majors or second-year students who had already completed a year of introductory biology. To further substantiate any findings from the MCQ, we asked a randomized subset of second-year cell biology students $(n=46)$ to "explain the relationship between chromosomes and DNA" in an open-ended short-answer question. 


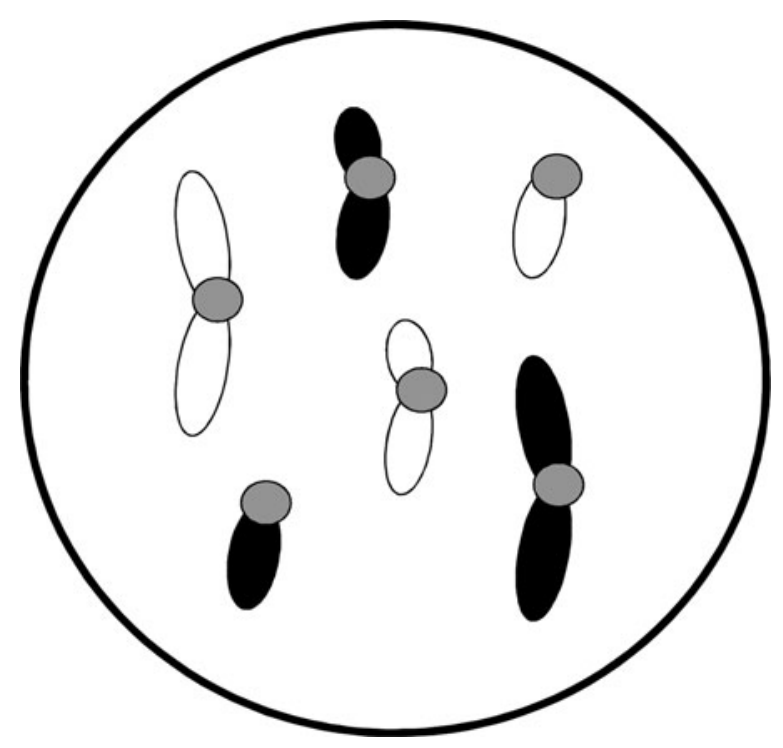

Figure 1. Diagram from the open-ended test question administered to students in two majors-level courses. Instructions described this figure as a precursor germ cell with three pairs of chromosomes. Note that unreplicated chromosomes are depicted, and one of the chromosome pairs is acrocentric, while the other two are metacentric.

To gauge student knowledge of chromosome structure and function, we asked midlevel students enrolled in cell biology $(n=71)$ and molecular biology $(n=96)$ courses to respond to selected questions in MCQ format from the IMCA (Shi et al., 2010). Given that a firm understanding of chromosome structure and function are central to these two gateway courses, valuable information about student models could be obtained from these populations.

To probe knowledge and ideas about chromosomes and genetic information flow from upper-level biology majors, we administered questions from the GCA (Smith et al., 2008) covering nine broad learning goals of genetics to students $(n=24)$ in a human genetics course. To enroll in this course, students must have completed introductory biology, cell biology, and molecular biology prerequisite courses. Although it is not required, half of these students had also taken a basic genetics course.

A second cohort of students $(n=131)$ enrolled in a separate offering of Cell Biology were tested for their conceptual understanding of the process of meiosis with an open-ended pretest) before the topic was covered in class. These students had been exposed to meiosis once already in college, and at least once prior to their undergraduate studies. Students were given a diagram depicting a precursor germ cell with three pairs of unreplicated chromosomes (Figure 1) and were asked to draw the major steps of meiosis to demonstrate the structure and behavior of the chromosomes during this process. The representation contained three maternal and three paternal chromosomes, depicted as three black and three white structures with matching sizes and shapes for each homologous pair. Student drawings were analyzed and coded using an emergent coding scheme that allowed us to identify common themes within the data and student responses.

\section{Meiosis Modeling Exercise}

Before students in the second cohort of Cell Biology received instruction on meiosis, they constructed their own models in groups of four to six students during recitation periods (84 students divided into 17 groups; 15 groups were videotaped). Students were asked to demonstrate what they thought were the key features of meiosis and to build a model that could be used to teach meiosis in a high school biology class. They were given manipulative materials to use for their modeling (e.g., pipe cleaners, construction paper, markers, string, wooden sticks, and colored beads). Students' models and explanations were videotaped but instructors did not attempt to correct mistakes during this exercise. Elements of students' models were coded as those that required an understanding of DNA and chromosomal structure (e.g., replication was correctly described in their model) with elements that did not (e.g., names of the meiotic phases were part of their model). Each group gave an oral description of their model. These verbal explanations were transcribed and combined into a single document that could be used to determine the frequency of terms used by students. A corresponding expert document to use as a comparison with student descriptions was constructed by combining a Proceedings of the National Academy of Sciences, USA (PNAS) review article on meiosis (Kleckner, 1996) and a textbook section describing meiosis (Alberts et al., 2002). A bidirectional gap analysis (Schoenfeld and Herrmann, 1982) was performed to show how terminology between experts and students differs. Word usage was counted and expressed as a percentage of total words in the document. Students' nonverbal vocalizations (such as "uh" and "um") were removed before analysis. Similarly, figures, titles, and citations were removed from the experts' version. Common English words that are not relevant to the topic (e.g., the, and, is) were included in the total but were ignored in the construction of the top 10 list for each document.

\section{Student Interviews}

In-depth interviews with five representative Introduction to Biology students were conducted to probe their understanding of chromosomal structure after the academic quarter in which they were taught cell division.

Upper-level biology students who had minimally completed the Cell Biology course (and who were not part of the group that completed the pretest and modeling exercises) were also solicited for in-depth interviews by personal invitation of the researchers. Fourteen students were interviewed in pairs using the diagram from Figure 1 as a starting point. An additional nine students were interviewed individually with paper questions and/or manipulative materials. All student interviews were videotaped.

\section{RESULTS}

\section{Biology Students Know Basic Structure of Chromosomes and DNA}

In assessments regarding concepts about DNA and chromosome structure, students enrolled in Introduction to Biology (freshman course) and Cell Biology and Molecular Biology (typically sophomores) were asked about the relationship 


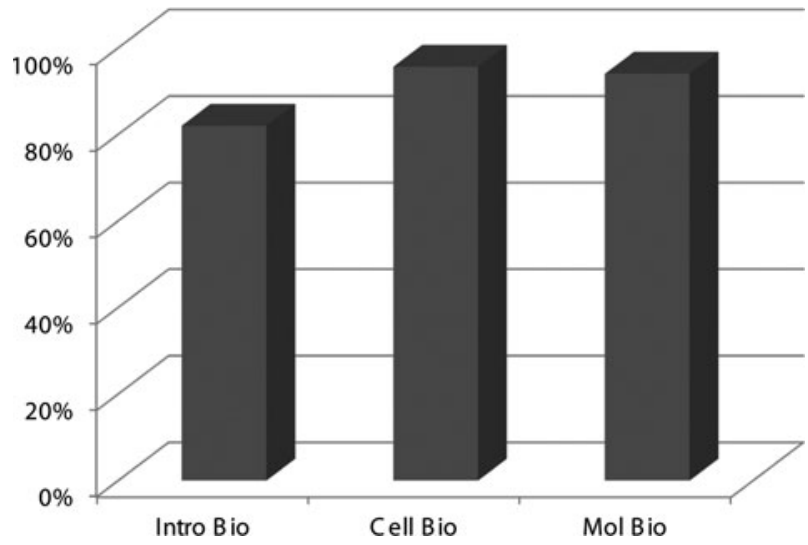

Figure 2. Biology students demonstrate knowledge of DNA and chromosome structure. Introduction to Biology (Intro Bio, $n=71$ ), Cell Biology (Cell Bio, $n=46$ ), and Molecular Biology (Mol Bio, $n=$ 96) students were asked to correctly identify the relationship between chromosomes and DNA in MCQ format (Intro Bio and Mol Bio) or open-ended format (Cell Bio).

between DNA and chromosomes using validated, published questions from the GLAI (Bowling et al., 2008) and IMCA (Shi et al., 2010). The vast majority of students at all levels could correctly answer questions about basic chromosome structure and the relationship between chromosomes and DNA (Figure 2).

In-depth interviews were conducted with Introduction to Biology students (freshmen) to probe their understanding of chromosomal structure. When asked to describe or define a chromosome, all five interviewees stated that chromosomes are made of DNA, although their descriptions were not necessarily complete:

Annie: Well, I'd probably say it's definitely composed of a lot of parts. It's DNA, proteins are inside it, wrapping it up making sure it's all nice and neat inside the cell, and essentially a chromosome is almost like a blueprint because it determines what the body's going to be made of, what it's going to be, and pretty much everything about it - that body or cell-in general.

Leah: A chromosome is a-it is uh-what you get when you condense long strands of DNA into it's uh DNAprotein complexes. It's what they use for-what the cells use for replication and to do meiosis.

Nate: It's a bunch of coiled DNA squished together, and then normally there are two of them bonded at the centromere.

Although second-year biology majors taking the Cell Biology course were capable of describing the composition of chromosomes in an open-ended question format, many made mistakes about the nature of genes. Analysis showed that $96 \%$ (44 of 46) students could clearly describe the correct relationship between chromosomes and DNA, but of the 20 students who expanded their answers to include the role of genes, half naively stated that genes coded for characteristics, traits, functions, or phenotypes, suggesting an unclear understanding of the central dogma. Students most likely learned this definition of a "gene" based on middle school or high school discussion of classical genetics and not from a molecular perspective. Only $50 \%$ of responders correctly wrote that genes

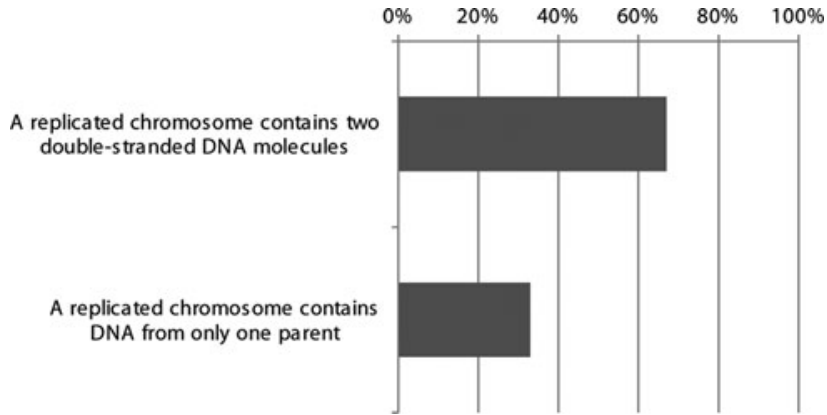

Figure 3. Cell Biology students do not transfer knowledge about chromosome structure to concepts involving genetic information. The IMCA (Shi et al., 2010) was administered to 68 students near the completion of the Cell Biology course. The percentage of students who correctly answered questions 19 and 20 (top bar and bottom bar, respectively) are shown.

coded for proteins. While we admit that this is an overly simplistic definition of a gene, since some genes code for functional RNAs (Pearson, 2006; Gerstein et al., 2007), the link between gene and trait requiring expression and function of a gene product is what seems to be missing from students' mental models.

\section{Biology Students Do Not Successfully Transfer Knowledge about Chromosome Structure to Concepts Involving Genetic Information}

Although the vast majority of students demonstrate understanding that chromosomes are composed of DNA (Figure 2), fewer students seem to apply this basic knowledge when presented with problems related to chromosome structure and information flow (Figure 3). Of the Cell Biology students tested, $67 \%$ knew that two double-stranded DNA molecules comprise a replicated chromosome, but only $33 \%$ believed that these same chromosomes contain genetic information from only one parent.

Advanced students entering Human Genetics also appear to have difficulty applying knowledge of basic chromosome structure to problems focusing on meiotic cell division, despite the fact that all students enrolled in this course had been exposed to the principles of meiosis numerous times (minimally in high school, Introductory Biology, Cell Biology, and Molecular Biology; nearly half had also taken Genetics). Figure 4 shows the results of selected questions from the GCA (Smith et al., 2008) given on the first day of class. The majority of the students could correctly identify representations of alleles on a pair of unreplicated chromosomes (71\%) and products of normal meiosis in terms of alleles $(67 \%)$, but few students grasped deeper-level components of the process. Only $27 \%$ of students identified the correct representation of alleles on replicated chromosomes, and $18 \%$ were able to recognize products of a nondisjunction event in terms of alleles. These latter questions probed beyond the superficial elements of chromosomes and meiosis, requiring integration of knowledge about heredity and chromosomal structure. The highlighted student errors indicate that the typical biology student has difficulty thinking about genes or alleles in the context of chromosomal behavior. This is clearly problematic 


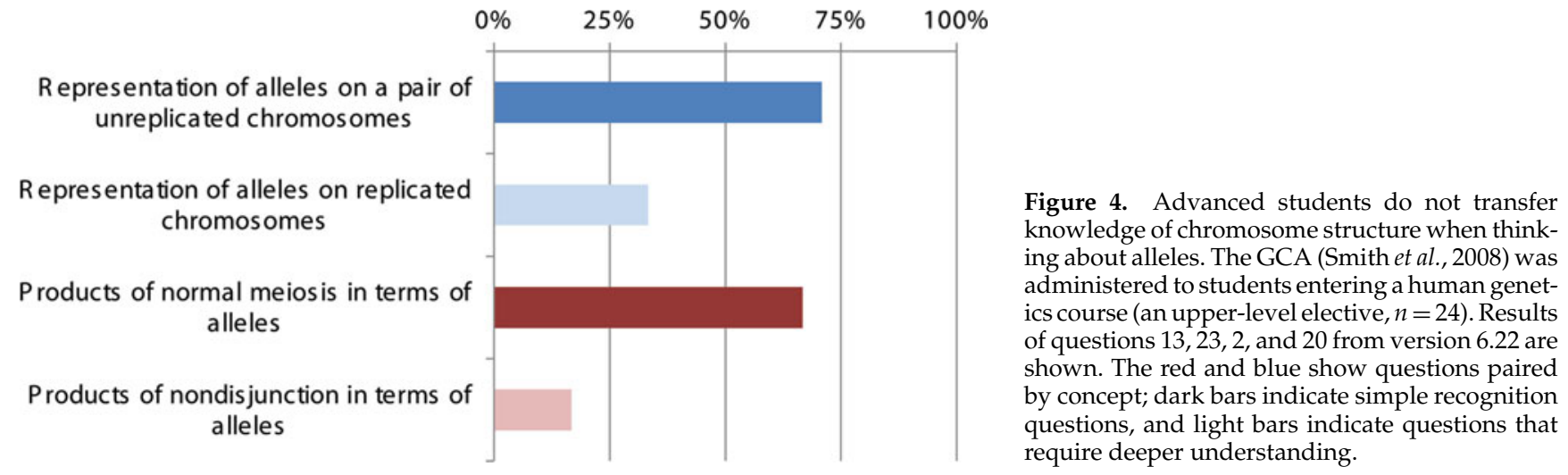

for students trying to understand complex cellular processes and genetic mechanisms.

\section{Many Students Do Not Use Their Understanding of Chromosome Structure When Asked to Construct Their Own Models of Meiotic Division}

A pretest assessment was administered to a total of 131 Cell Biology students to probe their understanding of meiotic division. Students were given a diagram (Figure 1) labeled as a "precursor germ cell with 3 pairs of chromosomes" and were asked to draw the major steps of meiotic division. Student drawings were analyzed and coded using an emergent coding scheme. Only $16 \%$ of students properly demonstrated the essential replication step in their models of meiosis (Figure 5). Many students (41\%) demonstrated replication but with a number of errors, such as the fusion of maternal and paternal chromosomes (similar to the formation by fertilization misconception identified by Smith, 1991), the addition of extra arms on the acrocentric chromosomes, or end-to-end fusion of acrocentric chromosomes. In fact, $35 \%$ of students did not adhere to the given model of chromosomes and added or subtracted chromosomal arms or entire chromosomes to make their mental models of this process fit the given situation.

Before any instruction on the topic of meiosis was given in class, students in the Cell Biology course were asked to construct models of meiosis using manipulative materials during their recitation periods. Similar to our observations of student drawings, most of these groups failed to develop complete and accurate models. Table 2 compares the essential features of each group's physical model. Working in groups had a positive effect on their final outcomes, but $64 \%$ of groups that presented a reasonable model still omitted important features, such as parental origin of chromosomes, allelic differences, and crossing over. The typical textbook representation uses size of the drawn chromosomes to indicate which ones are homologous and color to represent parental origin. Interestingly, only five groups (33\%) included any representation of differences between homologous chromosomes (as either containing different alleles or having different origins). Many of the groups (seven out of 15) used color and length of their pipe cleaner "chromosomes" redundantly; both features appeared to indicate which chromosomes paired together, and the concept of parental origin was completely missing. Two of the groups who did try to represent parental origin constructed incorrect hybrid chromosomes, in which one sister chromatid came from each parent.

Analysis of their explanations showed similar omissions of important concepts. While most groups could superficially demonstrate the overall picture of meiotic division (one cell with a complete set of paired chromosomes becomes four cells with one copy of each chromosome), the majority did not demonstrate a deeper understanding of molecular mechanisms and consequences that drive the process (Figure 6). For example, only $33 \%$ of the models included physical touching of chromosomes, only $21 \%$ of the students mentioned genetic content in their descriptions, and only $14 \%$ found it necessary to state the purpose of meiosis.

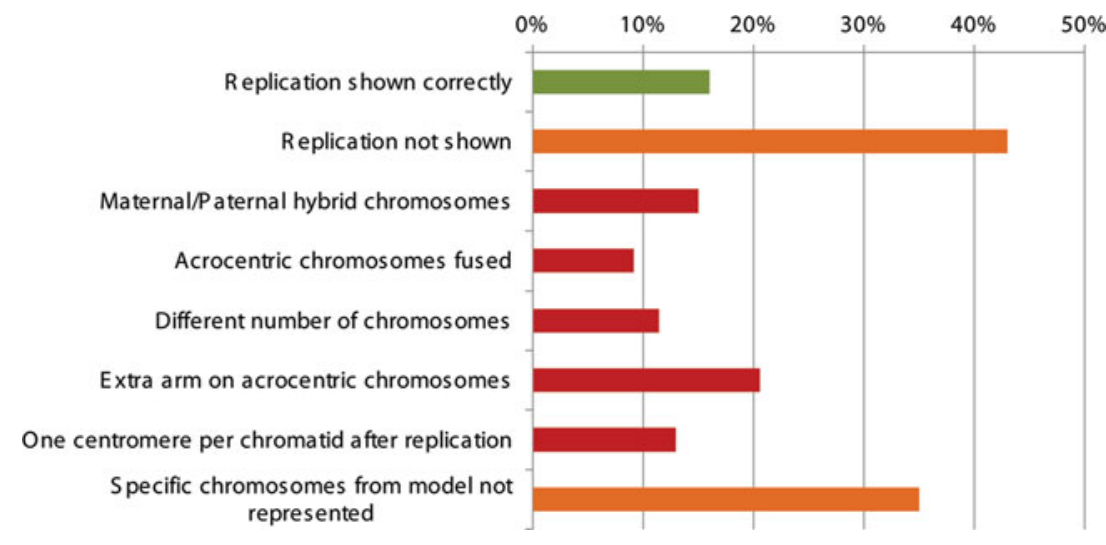

Figure 5. The vast majority of students did not demonstrate proper replication of chromosomes in the first step of meiosis. In open-ended question format, Cell Biology students $(n=131)$ were asked to draw the steps of meiosis starting with the diagram shown in Figure 1. Student representations of chromosomal replication were assessed. The green bar indicates the percentage of students who correctly demonstrated replication; red bars indicate fundamental errors; and orange bars indicate important omissions. Values do not add up to $100 \%$ because multiple categories may apply to a single drawing. 
Table 2. Features of the physical models of meiosis that student groups created ${ }^{\mathrm{a}}$

\begin{tabular}{|c|c|c|c|c|c|c|}
\hline Group & Meaning of size & Meaning of color & $\begin{array}{l}\text { Chromosome } \\
\text { structure }\end{array}$ & $\begin{array}{l}\text { Pairing during } \\
\text { meiosis I }\end{array}$ & Crossing over & Overall model \\
\hline 1 & No differences & Parental origin & Hybrid, unreplicated & $\begin{array}{l}\text { None (sister } \\
\text { chromatids only) }\end{array}$ & Not shown & Poor \\
\hline 2 & Homologous pairs & Homologous pairs & Correct & Homologous pairs & Not shown & Moderate \\
\hline 3 & Homologous pairs & Homologous pairs & Correct & Mispaired & Not shown & Moderate \\
\hline 4 & Homologous pairs & Homologous pairs & Correct & Homologous pairs & $\begin{array}{l}\text { Different alleles } \\
\text { represented }\end{array}$ & Good \\
\hline 5 & Homologous pairs & No differences & Correct & $\begin{array}{l}\text { Homologous pairs, } \\
\text { oriented incorrectly }\end{array}$ & Not shown & Moderate \\
\hline 6 & No differences & Parental origin $^{\mathrm{b}}$ & Correct & Homologous pairs & $\begin{array}{l}\text { Different alleles } \\
\text { represented }\end{array}$ & Good \\
\hline 7 & No differences & Homologous pairs & Correct & Homologous pairs & Not shown & Moderate \\
\hline 8 & No differences & Homologous pairs & Correct & Homologous pairs & Not shown & Moderate \\
\hline 9 & No differences & Homologous pairs & Correct & Homologous pairs & $\begin{array}{l}\text { Switching of segments } \\
\text { represented }\end{array}$ & Moderate \\
\hline 10 & Homologous pairs & Homologous pairs & Correct & Homologous pairs & Not shown & Moderate \\
\hline 11 & Homologous pairs & Homologous pairs & Correct & Homologous pairs & Not shown & Moderate \\
\hline 12 & Homologous pairs & Parental origin & Hybrid, replicated & Nonspecific & Not shown & Poor \\
\hline 13 & No differences & Homologous pairs & Correct & Homologous pairs & Not shown & Moderate \\
\hline 14 & Homologous pairs ${ }^{\mathrm{c}}$ & Parental origin & Correct & Homologous pairs & $\begin{array}{l}\text { Switching of segments } \\
\text { represented }\end{array}$ & Good \\
\hline 15 & No differences & Homologous pairs & Correct & Homologous pairs & Not shown & Moderate \\
\hline
\end{tabular}

aShaded boxes indicate places in which student models deviated from the classic representations used in most textbooks.

${ }^{b}$ This group used the same color for the chromosome arms for pairs of homologues but different-colored centromeres to represent origin.

${ }^{\mathrm{c}}$ This group showed only two pairs instead of three pairs.

Students did not demonstrate recognition that homologous DNA sequence is what drives the pairing of homologous chromosomes during meiosis. Only five of 15 groups included crossing over in their models and out of that subset, only one student stated that crossing over is necessary for the meiotic process. The remaining students described crossing over as a side effect. In this context, the term crossing over refers to synapsis, or physical linkage of replicated chromosomes during meiosis. To prevent the research team from influencing student thinking, team members asked students, "Is crossing over necessary for meiosis?" only after students introduced the term crossing over (no student used the terms "synapsis" or "recombination") or demonstrated physical touching of chromosome arms or switching of alleles during manipulation of their pipe-cleaner chromosomes. As physical interaction between replicated homologous chromosomes is essential for proper chromosome alignment and segregation during meiosis, describing the process as a side effect indicates that students do not consider chromosome structure when describing chromosome behavior. Each of the groups who participated in the study was given ample time to explain and demonstrate their model of meiosis. Transcripts were created from the 15 videotaped explanations; these totaled 2869 words, and word counts were performed to

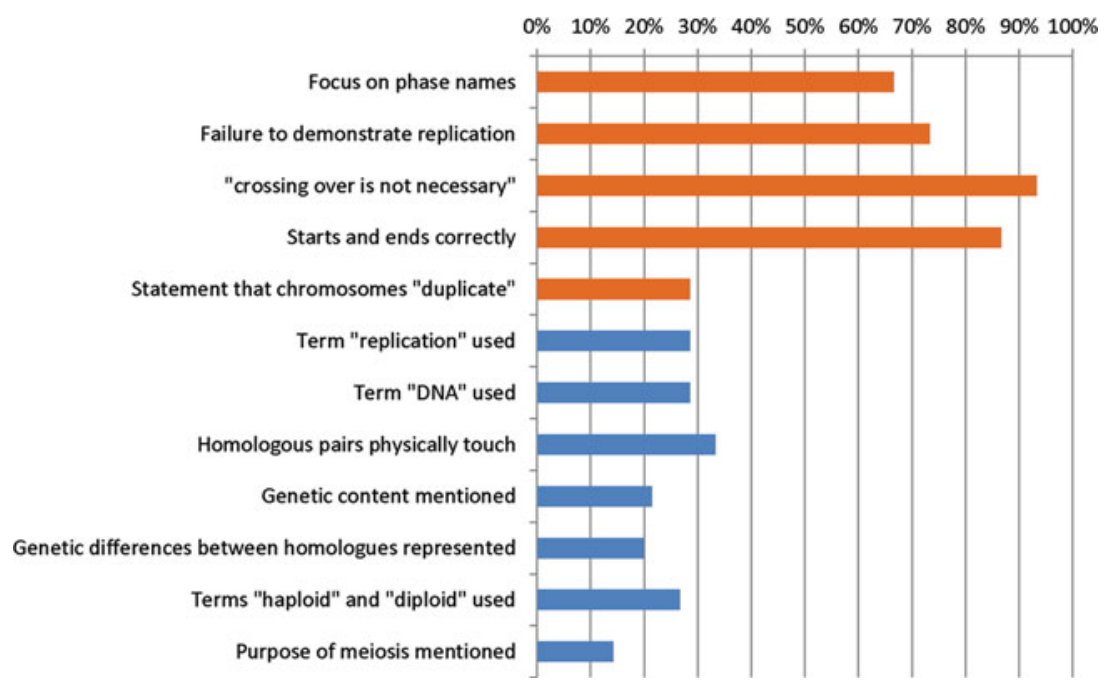

Figure 6. Content analysis of student models of meiosis in the Cell Biology class. A total of 14 groups of five to six students were given 30 $40 \mathrm{~min}$ to construct and explain a model of meiosis using manipulative materials. Their explanations were videotaped and analyzed for content. Blue bars indicate elements that demonstrate an understanding of the molecular structure/behavior of chromosomes; orange bars indicate elements that do not rely on a solid understanding of the relationship between DNA and chromosomes. 


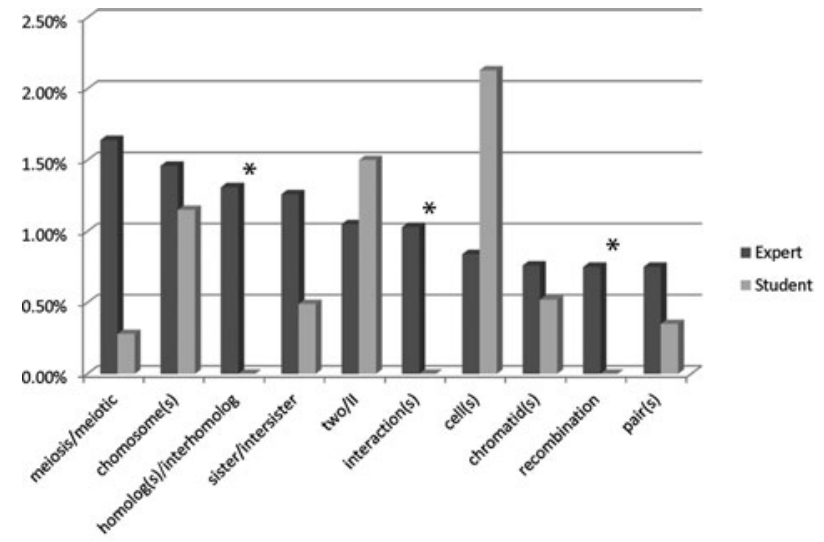

(A)

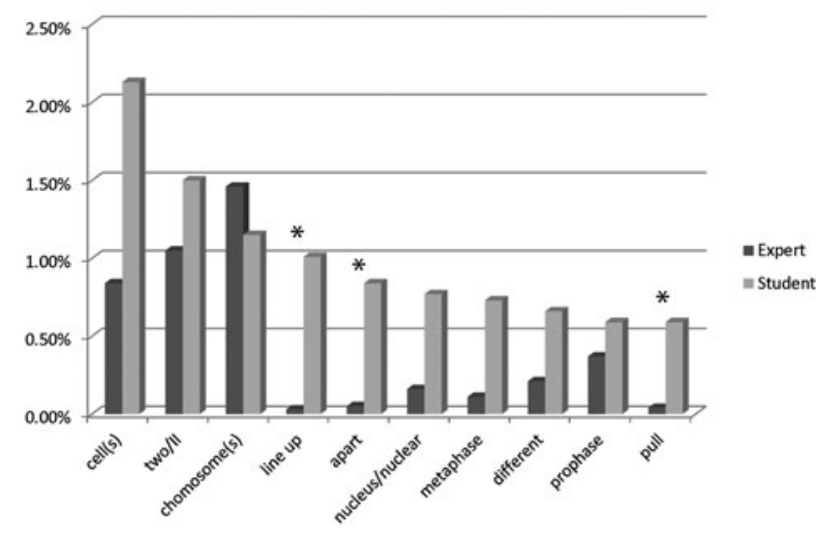

(B)

Figure 7. Gap analysis of terminology used by students and experts to describe meiosis. Transcripts (containing 2869 words) from student explanations of meiosis ( $n=15$ groups) and passages from a PNAS review article and a textbook passage (10,926 words combined) were analyzed to determine the terms most frequently used by students and experts (by percent) when describing meiosis. (A) The top 10 terms used by experts and (B) the top 10 terms used by students. Terms that were used $0.05 \%$ or less in one of the two groups are marked with an asterisk.

determine the terms most frequently used by biology students. As depicted in Figure 7, some of the most frequently used terms were cell, chromosome(s), line up, two, and apart. To compare student thinking with expert thinking, we combined the text from a PNAS review article titled "Meiosis: how could it work?" (Kleckner, 1996) and a passage on meiosis from Molecular Biology of the Cell, 4th Edition (Alberts et al., 2002), omitting all in-text citations, titles, author names, and figure legends. As depicted in Figure 7, the most frequently used terms by experts included chromosome(s), homologue/interhomologue, interaction(s), sister/intersister, and recombination. A bidirectional gap analysis (Schoenfeld and Herrmann, 1982) was performed to compare the top 10 expert terms with the top 10 terms that students use when describing the meiotic process.

Interaction was used 113 times $(1.03 \%)$ by experts and zero times by students. The same was observed for the words homologue and recombination, which were used $143(1.31 \%)$ and $82(0.75 \%)$ times, respectively, by experts. Students, on the other hand, focused on the words cell and nucleus more than experts did and used terms such as line up and pull apart to describe chromosome behavior. From these two analyses, we deduce that the typical student thinks about the process of meiosis in terms of overall cell and chromosome appearance. In contrast, for the expert, the process of meiosis can be explained by homology, interactions, and recombination, which are all driven by the molecular structure of chromosomes.

\section{Students Cannot Explain Phenomena Such as Homologous Pairing and Molecular Interactions of Chromosomes}

In-depth interviews with biology students complement the data gathered from the above classroom assessments. During interviews that focused on the process of meiosis, many students used the term DNA and displayed sophisticated knowledge about chromosomes and other relevant concepts, but then were not able to explain homologous pairing or molecular interactions of chromosomes.

In most of the interviews, students found the starting diagram (Figure 1) to be confusing. The drawing was specifically designed to be different from the typical textbook diagram in several ways, in order to see whether students could apply the knowledge they had learned in one format to a slightly different situation: chromosomes were unreplicated, there was an odd number of pairs of chromosomes, and one pair of chromosomes was acrocentric. Although some students may not have been previously exposed to an image of an acrocentric chromosome, it served as an important opportunity for students to demonstrate knowledge transfer-utilizing chromosomal knowledge in a new context. In the passage below, two students erroneously solve the problem of two unreplicated acrocentric chromosomes by pairing them together, end-to-end:

Interviewer: It seemed like...these chromosomes [indicating the acrocentric pair] confused you a little bit. Can you talk a little about that?

Brianna: Because it didn't have both of these [arms] on both sides, I was a little confused about how it would in the next phase-how it would split off and cross over.

Interviewer: Have you ever seen a chromosome that looks like that before?

Brianna: I probably have, but I don't recall.

Alexandra: I think we did it in the. . are they called karyotypes? Like the pictures where you can see that oh, 21 has like three, and that's like...trisomy.... But usually the diagrams in the book have like the nice ones like this [indicating metacentric chromosome], like oh, this is like how they split. So I've seen like in "real life" like the different shape chromosomes, but the diagrams are always like the nice perfect, full chromosomes.

[Interviewer repeats that the acrocentric chromosomes were confusing because "they didn't look like the book" and gets strong confirmation from both. Later in the interview Brianna admits to still being confused about the acrocentric chromosome:]

Brianna: It's not the book orientation.

In a separate interview (also using Figure 1 as a starting point) Matt and Alyssa found the two acrocentric chromosomes to be confusing and resolved the issue by pairing 
(without replicating) the two acrocentric chromosomes together in their model, so their "cell" just before meiosis I contained four replicated chromosomes and one hybrid chromosome composed of a maternal and paternal (unreplicated) chromosome. The students puzzled over the issue of five chromosomes in the passage below:

Interviewer: Good, so let's start out by talking about what you did. So the first thing that you had to do here was you had to figure out what this picture meant. So can you tell me what this picture meant to you and if there was anything confusing about it?

Alyssa: Well it says 3 pairs of chromosomes, so that would mean six, but if you pair them together there is only...

\section{Matt: Three}

Alyssa: I mean, that means six separate chromatids and there is five.

Interviewer: There's five?

Matt: There are these two, these two, and these two.

Interviewer: So these you see these [acrocentric chromosomes] as being different from these [metacentric chromosomes]?

Alyssa: Yeah

Interviewer: Have you ever seen a chromosome look like that?

Matt: Not really

Alyssa: Not really

Interviewer: So that was kind of confusing to you?

Matt: Yeah

Interviewer: Okay. So what did you end up deciding to do about that?

Alyssa: We just paired it as one.

Matt: Yeah we made it as one chromosome.

Because experts have a clear conceptual model of basic chromosome structure, they do not view textbook drawings and diagrams in the same way students do and cannot even predict the interpretations that students will make looking at the same picture (Benson, 1997). In the above example, the students recognize that they have been exposed to different representations of chromosomes, but they do not have the facility to move between them. Any difference between representations may be a source of confusion for the novice, especially if he or she does not transfer prior knowledge of chromosomes to this new situation. Thus, elements considered to be extraneous details (such as the position of a centromere) to an expert may become a roadblock for the novice.

\section{Students Do Not Properly Transfer Knowledge of Chromosome Structure to Molecular Mechanisms}

Students often revealed a poor cognitive sense of chromosomes or DNA as molecules. Each of the students in this part of the study had completed at least a year of chemistry, so presumably they had learned about molecular behavior.
However, in this biological context, students did not demonstrate the understanding that matter is subject to different kinds of forces and experiences different phenomena on a molecular or atomic scale than macroscopic objects or whole organisms do.

In the following example, Trisha and Kari drew homologous chromosomes (unreplicated) touching at the centromeres:

\begin{abstract}
Interviewer: Do you think that they touch each other at any place other than the centromere

[Pause]

Kari: Hm. Maybe they touch, but they're not, I mean, connected.

Trisha: Yeah, 'cause chromosomes are like DNA supersuper tightly packed, so if it touches it's like, I don't know, they don't affect each other by touching. It's not like you can magically rub off part of the DNA or something.
\end{abstract}

In several of the interviews, students were asked how homologous chromosomes find their mates. All showed surprise at first and hesitated before answering. They clearly had never been asked to think about this fundamental question before:

Interviewer: What do you think allows them to find each other? How do you get homologous chromosomes coming together? [pause]

Matt: Mating call? Just kidding. . Probably like a hydrophilic attraction or something along those lines. Something like an electronegative attraction.

Interviewer: How would that be specific for pairing them?

Alyssa: Well they cross over, so I'm assuming that they would try to find chromosomes that best match what they have on each other-like the type of like genes that they have on it.

[Matt and Alyssa agree that crossing over involves physical touching of chromosomes and chemical bonds, but when asked if that is important for the process of pairing, they say no.]

Matt: It's a side effect.

James offered a creative solution to the problem of homologous pairing in the following passage:

James: My guess is that there would be some sort of chaperone protein, that interact[s] with similar chromosomes. But I don't know though, the specifics of that.

Interviewer: So you're hypothesizing that maybe there are just specific proteins for each chromosome pair so the homologous ones can find each other?

James: I don't know if we talked about that, but I think that would be the only way that it could happen.

All of the above passages are representative of typical student responses. They are not special cases. We have observed 
time after time that students do not think about the molecular properties of DNA when asked about chromosomal behavior.

\section{DISCUSSION}

As in the classic definition of transfer, we argue that the typical biology student "knows" about chromosomes and chromosome structure in one context but cannot properly use the knowledge in another. Through coded worksheet data, formative assessments, modeling exercises, and student interviews, we have demonstrated that students understand the relationship between chromosomes and DNA, are proficient at understanding the structure of a chromosome, and can identify the products of meiosis (specialized cell division) in terms of alleles. Far fewer, however, reconcile the structure of a chromosome with the structure of DNA, and even fewer students use this knowledge when thinking about genetic information contained within chromosomes or about information flow (central dogma).

While student misunderstanding of central dogma has been described by other researchers (Lewis and Kattmann, 2004), we suggest that this observation be interpreted in a broader context. Students fail to understand complex processes, not because they do not understand the underlying "bits" of information but, rather, because they miss critical connections tying the molecular structure of chromosomes with the central dogma. This also suggests that future work should focus not only on the limits of conceptual understanding, but also on the applicability of known concepts to unfamiliar contexts - the definition of transfer.

We believe that biology students do not transfer their knowledge of DNA between different levels of representation they may encounter: images of whole chromosomes (either photographs or diagrams of condensed chromosomes in cell division), submicroscopic images (e.g., DNA sequence or chemical structure), or symbolic images (e.g., a diagram of a gene represented with boxes for promoter and coding regions). This is a similar framework to Johnstone's Triangle in chemistry, in which students have trouble moving between macroscopic (e.g., salt crystals), submicroscopic (e.g., a chemical structure diagram), and symbolic (e.g., a chemical equation) representations of the same phenomenon (Johnstone and Mahmoud, 1980). In our study, very few students properly demonstrated the essential replication step when asked to draw the major steps of meiosis when starting with unreplicated chromosomes. Many students made errors when trying to demonstrate replication (e.g., adding extra arms on the acrocentric chromosomes in lieu of proper chromosomal replication) or failed to include a replication step at all. We suggest the following explanation: When students are presented with a representation of a chromosome (as in Figure 1), they work with only one mental model (something akin to a macroscopic stick) to solve the problem. Most students do not think of chromosomes on the molecular level (DNA sequence) when presented with a representation of a whole chromosome. If they did, far fewer would probably "forget" to include a DNA replication step or make illogical errors, such as fusing two unreplicated chromosomes end-to-end, adding extra arms on acrocentric chromosomes, or simply adding/deleting chromosomes to create an even number of chromosomes after the second meiotic division.

The students we tested seemed to rely on surface features of chromosomal representations in much the way described by Chi and colleagues (1981), when strategies used by undergraduate physics students (novices) and advanced physics graduate students (experts) to categorize various physics problems were investigated. Novices relied on surface features and structures found within the problem, such as the presence of pulleys, inclined planes, ramps, and springs, while experts used laws of physics, such as conservation of energy to determine how the problem should be approached. Experts, then, are able to handle slight changes in representation, because they rely on the abstract principles presented within the problems. Experts and novices also deal differently with chemical representations. For example, experts (professional chemists) and novices (undergraduate chemistry students) constructed different categories when presented with 14 cards containing either a graph, image, chemical equation, or a link to a computer animation about various chemical phenomena (Kozma and Russell, 1997). Novices tended to group representations of the same media type together (equations), while experts relied more on conceptual reasoning in their sorting tasks. Typical biology students do not think about DNA when they are presented with a macroscopic representation of a chromosome; we believe they only see surface features (stick-like chromosome models), not molecules, and this prevents them from transferring knowledge of basic chromosome structure to scenarios involving replication and division.

Although the phenomenon of transfer has been studied most deeply by those outside biology (e.g., Perkins and Salomon, 1988; Mestre, 2002; Schwartz et al., 2011), the work can and should inform biology educators in their own classroom design. Schwartz and Bransford (1998). described increased leaning and knowledge transfer in students who first created graphs to describe data sets from psychology experiments, compared with peers who summarized a chapter on the same experiments. In another case, students who invented a mathematical formula before instruction displayed increased transfer of knowledge compared with students who were simply told the formula beforehand (Schwartz and Martin, 2004). One way to increase knowledge transfer, then, is to prime or prepare students by allowing them to construct their own models, from which they will invent generalizations to apply in other contexts.

Our work implies that instruction should focus as much on the transfer of concepts as on the mastery of the concepts themselves. Biology education research has begun to mirror the evolution of physics education research, moving from "misconception" models of understanding to more fluid theories involving transfer and activation of resources. For example, an Invent with Contrasting Cases pedagogy (Schwartz et al., 2011) could be implemented, in which students would be presented with several images of DNA (at the macroscopic, molecular, and symbolic levels) simultaneously and asked to create a model or description of DNA to which all representations would apply. Instructors might make a conscious effort to focus on the relationship between DNA and chromosomes in as many contexts as possible. For example, when students are given genetics problems focusing on alleles and transmission of genetic material, instructors should challenge 
students to define an allele at the molecular level. When students see a typical textbook image of "crossing over" during meiosis I, the instructor should probe at their understanding of chromosomal behavior (e.g., How do homologous chromosomes align? What does the term "homologous" mean?) to help students transfer their basic knowledge of chromosome and DNA structure when thinking about complex cellular processes.

In previous work, we showed how a constructivist activity can be applied in a biology setting to increase knowledge transfer of key points in meiosis. A key feature of this work was that biology students were first primed for learning by creating their own models of meiosis using manipulative materials (Wright and Newman, 2011). In the activity that followed, instructors probed students about chromosomal structure at the molecular level, in order to help them make connections between structure and behavior. In the work presented here, we delved deeper into students conceptual models and understanding of the molecular nature and behavior of chromosomes by investigating the elements and terminology that were used, or omitted, from their meiosis models (Figures 6 and 7). An interesting finding between the two analyses was that only $19 \%$ of individual students drew correct representations of chromosomes going through the process of meiosis in a preactivity assessment (Wright and Newman, 2011), whereas $85 \%$ of group models analyzed in this work were at least moderately correct (Table 2). It has been well documented in the literature that peer discussion improves performance on conceptual tasks (e.g., Smith et al., 2009), so future activities aimed at improving transfer should involve some degree of group discussion.

In-depth interviews with a number of students confirmed many of our findings. An image of an acrocentric chromosome posed a major issue for students, because, students explained, it did not look like something they were used to seeing in a textbook figure. This image was chosen specifically to evaluate transfer ability. Students admitted to being unfamiliar with that type of representation and were unable to see beyond the surface the way an expert would, so they could not make sense of the image. In other words, it did not activate prior knowledge about chromosome or DNA structure. In the analysis of student drawings of meiosis, it was found that a significant percentage drew two acrocentric chromosomes fused together (end-to-end) or even created an alternative number of chromosomes in their drawings, because they could not resolve the scenario. These manipulations may be compared with the phenomenon of "absurdism" observed when physics students were presented with a difficult problem involving the relativity of simultaneity (a challenging concept for the typical student). In these situations, students commonly gave up logic or tried to resolve a problem or paradox using scientific mechansims/properties that do not exist (Scherr, 2007). Likewise, we know that chromosomes do not routinely fuse, and unreplicated maternal and paternal chromosomes do not pair to make hybrid chromosomes, yet these explanations were offered several times by students when their understanding was challenged.

Although students have knowledge of DNA and chromosomal makeup, they struggle when asked to think about mechanisms (e.g., How do the homologous chromosomes find their mates?). Students did not think to use knowledge they had learned in other contexts - the base pairing of DNA, for example-in order to solve the problem. In all of the student explanations we analyzed (during the meiosis modeling exercise and in-depth interviews), there was only one instance of a student who correctly demonstrated and explained the significance of crossing over (synapsis, or physical linkage of the chromosomes) to the process of meiosis. Most students had no idea how homologous pairs of replicated chromosomes aligned and demonstrated no understanding of the molecular nature of chromosomal behavior. We also found that terms like "interaction" and "recombination" were frequently used by experts (Figure 7) but not by students, who instead suggested mechanisms that did not involve the structure of DNA. Their chromosomal models seemed more appropriate to proteins (e.g., hydrophilic, electrostatic) or macromolecular objects (e.g., "they touch but don't interact") than the simple base-pairing that DNA structure suggests.

Activation of appropriate resources is essential when presented with a new problem. Resources are not necessarily incorrect or misleading but can become so if applied to a particular problem inappropriately, and experts rely on different resources than novices would in the same context (reviewed by Hammer, 2000). For example, when asked how chromosomes pair, an expert might rely on resources based on molecular interactions, whereas students are more likely to utilize knowledge about macroscopic objects, such as puzzle pieces fitting together. Future work will focus on identifying and testing elements in representations that help students think about the underlying structure of chromosomes or activate appropriate cognitive resources that would allow them to use their knowledge when thinking about a complex cellular process.

\section{ACKNOWLEDGMENTS}

We thank D. Carter, A. Hudson, and P. Shipman for help with collecting formative assessment data. We also thank M. Osier and R. Rothman for insights about teaching genetics to undergraduates. We owe particular gratitude to T. Kim, S. Franklin, and N. Pelaez for helpful discussions.

\section{REFERENCES}

Alberts B, Johnson A, Lewis J, Raff M, Roberts K, Walter P (2002). Molecular Biology of the Cell, 4th ed., New York: Garland Science, chap. 20.

Bahar M, Johnstone AH, Hansell MH (1999). Revisiting learning difficulties in biology. J Biol Educ 33, 84.

Barnett SM, Ceci SJ (2002). When and where do we apply what we learn? A taxonomy for far transfer. Psychol Bull 128, 612-637.

Benson PJ (1997). Problems in picturing text: a study of visual/verbal problem solving. Tech Comm Quart 6, 141-160.

Bowling BV, Acra EE, Wang L, Myers MF, Dean GE, Markle GC, Moskalik CL, Huether CA (2008). Development and evaluation of a Genetics Literacy Assessment Instrument for undergraduates. Genetics 178, 15-22.

Bransford JD, Schwartz DL (1999). Rethinking transfer: a simple proposal with multiple implications. Rev Res Educ 24, 61-100.

Brown CR (1990). Some misconceptions in meiosis shown by students responding to an advanced level practical examination question in biology. J Biol Educ 24, 182-186. 
Chi MTH, Feltovich PJ, Glaser R (1981). Categorization and representation of physics problems by experts and novices. Cogn Sci 5 , 121-152.

Creswell JW (2007). Qualitative Inquiry and Research Design: Choosing among Five Approaches, Thousand Oaks, CA: Sage Publications.

Dikmenli M (2010). Misconceptions of cell division held by student teachers in biology: a drawing analysis. Sci Res Essay 5, 235-247.

Fisher KM, Lipson JI, Hildebrand AC, Miguel L, Schoenberg N, Porter N (1986). Student misconceptions and teacher assumptions in college biology. J Coll Sci Teach 15, 276-280.

Gerstein MB, Bruce C, Rozowsky JS, Zheng D, Du J, Korbel JO, Emanuelsson O, Zhang ZD, Weissman S, Snyder M (2007). What is a gene, post-ENCODE? History and updated definition. Genome Res 17, 669-681.

Hammer D (2000). Student resources for learning introductory physics. Am J Phys 68, S52-S59.

Holstein JA, Gubrium JF (2003). Inside Interviewing: New Lenses, New Concerns, Thousand Oaks, CA: Sage Publications.

Johnstone AH, Mahmoud NA (1980). Isolating topics of high perceived difficulty in school biology. J Biol Educ 14, 163-166.

Kelly R, Jones L (2007). Exploring how different features of animations of sodium chloride dissolution affect students' explanations. J Sci Educ Technol 16, 413-429.

Kelly RM, Jones LL (2008). Investigating students' ability to transfer ideas learned from molecular animations of the dissolution process. J Chem Educ 85, 303.

Kindfield ACH (1991). Confusing chromosome number and structure: a common student error. J Biol Educ 25, 193-200.

Kindfield ACH (1994a). Biology diagrams: tools to think with. J Learning Sci 3, 1-36.

Kindfield ACH (1994b). Understanding a basic biological process: expert and novice models of meiosis. Sci Educ 78, 255-283.

Kleckner N (1996). Meiosis: how could it work. Proc Natl Acad Sci USA 93, 8167-8174.

Kozma R, Russell J (1997). Multimedia and understanding: expert and novice responses to different representations of chemical phenomena. J Res Sci Teach 34, 949-968.

Lave J (1988). Cognition in Practice: Mind, Mathematics and Culture in Everyday Life, Cambridge, UK: Cambridge University Press.

Lewis J, Kattmann U (2004). Traits, genes, particles and information: re-visiting students' understandings of genetics. Int J Sci Educ 26, 195-206.

Lewis J, Leach J, Wood-Robinson C (2000). All in the genes?-young people's understanding of the nature of genes. J Biol Educ 34, 74-79.

Marbach-Ad G (2001). Attempting to break the code in student comprehension of genetic concepts. J Biol Educ 35, 183-189.

Martin PY, Turner BA (1986). Grounded theory and organizational research. J Appl Behav Sci 22, 141-157.
Mestre JP (2002). Probing adults' conceptual understanding and transfer of learning via problem posing. J Appl Dev Psychol 23, 9-50.

Mestre JP (2005). Transfer of Learning from a Modern Multidisciplinary Perspective, Charlotte, NC: Information Age Publishing.

Mills Shaw KR, Van Horne K, Zhang H, Boughman J (2008). Essay contest reveals misconceptions of high school students in genetics content. Genetics 178, 1157-1168.

Pearson H (2006). What is a gene? Nature 441, 398-401.

Perkins DN, Salomon G (1988). Teaching for transfer. Educ Leadership 46, 22-32.

Perkins DN, Salomon G (1992). Transfer of learning. In: International Encyclopedia of Education, Oxford, UK: Pergamon Press.

Scherr RE (2007). Modeling student thinking: an example from special relativity. Am J Phys 75, 272-280.

Schoenfeld AH, Herrmann DJ (1982). Problem perception and knowledge structure in expert and novice mathematical problem solvers. J Exp Psychol Learn Mem Cogn 8, 484-494.

Schwartz D, Martin T (2004). Inventing to prepare for future learning: the hidden efficiency of encouraging original student production in statistics instruction. Cogn Instruct 22, 129-184.

Schwartz DL, Bransford JD (1998). A time for telling. Cogn Instruct $16,475-5223$.

Schwartz DL, Chase CC, Oppezzo MA, Chin DB (2011). Practicing versus inventing with contrasting cases: the effects of telling first on learning and transfer. J Educ Psychol 103, 759-775.

Shi J, Wood WB, Martin JM, Guild NA, Vicens Q, Knight JK (2010). A diagnostic assessment for introductory molecular and cell biology. CBE Life Sci Educ 9, 453-461.

Smith MK, Wood WB, Adams WK, Wieman C, Knight JK, Guild N, Su TT (2009). Why peer discussion improves student performance on in-class concept questions. Science 323, 122-124.

Smith MK, Wood WB, Knight JK (2008). The Genetics Concept Assessment: a new concept inventory for gauging student understanding of genetics. CBE Life Sci Educ 7, 422-430.

Smith MU (1991). Teaching cell division: student difficulties and teaching recommendations. J Coll Sci Teach 21, 28-33.

Stewart J, Dale M (1989). High school students' understanding of chromosome/gene behavior during meiosis. Sci Educ 73, 501-521.

Stewart J, Hafner B, Dale M (1990). Students' alternate views of meiosis. Am Biol Teach 52, 228-232.

Strauss AL, Corbin JM (1997). Grounded Theory in Practice, Thousand Oaks, CA: Sage Publications.

Wood-Robinson C, Lewis J, Leach J (2000). Young people's understanding of the nature of genetic information in the cells of an organism. J Biol Educ 35, 29-36.

Wright LK, Newman DL (2011). An interactive modeling lesson increases students' understanding of ploidy during meiosis. Biochem Mol Biol Educ 39, 344-351. 